\title{
"What drives loyal fans of brand pages to take action? The effects of self-expansion and flow on loyal page fans' sharing and creation activities"
}

\author{
Angeliki Nikolinakou ${ }^{1} \cdot$ Joe Phua $^{2} \cdot$ Eun Sook Kwon ${ }^{3}$
}

Revised: 16 May 2021 / Accepted: 28 May 2021 / Published online: 3 July 2021

(c) The Author(s), under exclusive licence to Springer Nature Limited 2021

\begin{abstract}
Consumer-driven sharing and creation activities are valuable engagement activities as they help spread awareness and interaction for brands on social media. Loyal fans of brand pages are an important audience for brand-related social media engagement, as they are more likely to recommend and advocate for brands. However, little is known about what motivates loyal fans to engage in these valuable activities. This study takes a novel approach by examining self-expansion as a driver that prompts loyal fans to action. When brands offer self-expansive opportunities on their pages, in the form of new knowledge, new perspectives (e.g., awareness on social issues) and exciting experiences, fans may incorporate these in their sense of self (self-page inclusion) and reciprocate by investing their own resources to brand pages. A survey was conducted with 238 millennial users who have a favorite brand page on Instagram. The findings show that the more fans gain opportunities for self-expansion from their favorite pages, the more likely they are to share and create brandrelated content. Brand page flow and self-page inclusion are also important drivers. Further, specific page experiences are identified that may enhance the effects of these drivers. Managerial implications are included on how to apply these findings to social media content strategy.
\end{abstract}

Keywords Self-expansion theory $\cdot$ Social media strategy $\cdot$ User-generated content $\cdot$ Content strategy $\cdot$ Social media sharing

\section{Introduction}

Marketers consider social media content strategy to be an important part of their overall marketing initiatives and are increasingly using their social media brand page content to engage consumers (Hubspot 2020). With $90 \%$ of businesses

Angeliki Nikolinakou

aggeliki.nikolinakou@gmail.com

Joe Phua

joephua@uga.edu

Eun Sook Kwon

exkgpt@rit.edu

1 Athens, Greece

2 Department of Advertising and Public Relations, Grady College of Journalism and Mass Communication, University of Georgia, 120 Hooper Street, Athens, GA 30602-3018, USA

3 School of Communication, College of Liberal Arts, Rochester Institute of Technology, 92 Lomb Memorial Dr., Rochester, NY 14623, USA in the USA using social media as a marketing tool (Statista 2019), social media is viewed by companies as an effective tool for increasing brand awareness, brand community engagement and growing brand audiences. Research by Sprout (2020) suggests that consumers are more likely to buy and increase their spending on brands they follow on social media. Further, $45 \%$ of consumers state that they are likely to unfollow a brand on social media if they find the content of brand pages to be irrelevant (Sprout 2020). Businesses are not only focusing their efforts on producing stimulating brand page content to engage their followers and fans, but they are especially interested in motivating fans to share brand page content and create content (user-generated content) for their brands on social media (Social Media Today 2018). Consumer-driven sharing and creation activities are considered valuable engagement activities as they help spread awareness and interaction with brands on social media, more so than consumption activities (e.g., browsing and liking) (John 2017).

Previous research studies have focused on social media content that may elicit brand-related sharing or creation 
activities (e.g., Ashley and Tuten 2015; Carlson et al. 2017a; Tafesse 2016). For example, Yuki (2015) found that brand-related content on social media that provides social currency, elicits happiness, is perceived as useful and employs storytelling is more likely to be shared on social media compared to other types of content. Further, creative strategies on social media that appeal to users' senses, offer exclusive benefits, enhance users' self-esteem (Ashley and Tuten 2015), include photos, videos and links, mention other users or celebrities, explain product characteristics and introduce new brands, are more likely to engage users on social media (Tafesse 2016). Studies have also examined types of audiences in relation to brand-related sharing and creation activities (Nikolinakou and Phua 2020; Van Meter et al. 2018). Van Meter et al. (2018) show that audiences that are more attached to social media platforms are also more likely to engage in meaningful activities such as sharing brand-related content and advocating for brands on social media. Further, users driven by conservation or those who value safety and security tend to share more promotional content compared to other types of users. Users driven by self-enhancement, or users who value power and achievement, tend to share more expert information and write reviews for brands, compared to other audiences (Nikolinakou and Phua 2020). Self-enhancement, affiliation, entertainment, information-seeking and personal identity motivations have also been found to be important motivations for brand-related social media engagement (Muntiga 2011).

Research findings indicate that loyal fans of brand pages, fans who consider a brand page as their favorite brand page, may be an important audience for brand-related social media engagement, as they are more likely to recommend and advocate for brands on social media compared to users who are followers or fans of a brand page (Kleine-Kalmer 2015; Van Meter et al. 2018; Zaglia 2013). Thus, companies like Starbucks and Coke-Cola are focusing on engaging their loyal fans with social media content (Bullock 2019). However, little is known about loyal fans' motivations to engage in such valuable behaviors and the specific benefits and experiences that brands may offer on their pages to address loyal fans' motivations.

We posit that brands should offer opportunities for selfexpansion on their social media pages, as self-expansion may motivate loyal fans to share and create brand-related content. Self-expansion theory in the context of close relationships emphasizes a central motive whereby individuals employ close relationships to expand their sense of self, through acquisition of new skills, resources and perspectives from their partners (Aron et al. 2013). We argue that when brands offer self-expansive opportunities on their social media pages, in the form of new knowledge, skills, new experiences and opportunities for self-improvement (e.g., educational content, content that raises awareness on important social issues, content that promotes living a healthy life, etc.), loyal fans may incorporate these in their sense of self-via a process of self-page inclusion, in order to enrich and expand their identity. In return, fans may reciprocate by investing their resources to brand pages, through sharing and creating content for brands on social media. We also examine flow as a driver for brand-related engagement. Flow is an implicit emotional and physiological state of intense concentration that has been found to prompt creativity (Cseh et al. 2015). We contend that states of flow experienced in relation to brand pages will implicitly drive self-expression and action in the form of sharing and creation activities on social media. We also identify brand experience types (e.g., novelty, senses, intellectual, emotional, social, relationships, etc.) that enable loyal fans' self-expansion, self-page inclusion and flow. This research is among the first to consider the implications of self-expansion theory on social media content strategy, providing recommendations on how marketers can apply self-expansion and flow theories to their content in order to motivate brand page fans to engage in valuable brandrelated behaviors on social media.

In the literature review section, we examine self-expansion theory and how it applies to brands and social media, as well as the relationships between self-page inclusion, flow and self-expansion. We also consider the potential effects of self-expansion, attachment and self-page inclusion on brand-related engagement. Additionally, we hypothesize that specific brand page experiences may serve as potential drivers of self-expansion, attachment and self-page inclusion. In the results section, we present the findings of the Structural Equation Model used to test the above relationships. In the discussion section, we discuss the importance of self-expansion, self-page inclusion and flow for brandrelated engagement. The managerial implications discuss the implications of the findings for brand pages and how companies can elicit self-expansion, self-page inclusion and flow in order to motivate loyal fans to engage in brand-related sharing and content creation activities.

\section{Literature review, theoretical framework and hypotheses}

\section{Self-expansion via self-other inclusion}

\section{Self-expansion theory}

Self-expansion theory posits that individuals have an innate need for self-expansion by seeking out experiences that enable personal growth. Self-expansion is the motivation to increase resources, perspectives and 
identities to develop one's ability to achieve life goals (Aron et al. 2013; Mattingly and Lewandowski 2014b, 2013). Individuals seek to expand their physical and material influence (e.g., possessions and power), intellectual identity (e.g., knowledge and skills), their social identity-by including others in their lives, as well as a broader understanding of life and the world (e.g., religion, philosophy, wisdom from life experiences) (Aron et al. 2013). The focus of self-expansion motivation is not in achieving long-term goals but in strengthening one's efficacy in attaining these goals. Self-expansive activities may increase perseverance in goal-pursuit, broaden and amplify self-perceptions and enhance job satisfaction and commitment (Mattingly and Lewandowski 2013, 2014a; McIntyre et al. 2014). Self-expansion motivation has been examined in relational (e.g., Aron et al. 2000, 2006) and non-relational (e.g., Mattingly and Lewandowski 2013; $2014 \mathrm{a}, \mathrm{b})$ contexts.

\section{Self-expansion theory of close relationships}

According to the self-expansion model in close relationships, one way individuals self-expand is via close relationships. Individuals are drawn to form close connections with those that add value to their physical, social and intellectual resources, enabling them to grow (Aron et al. 2013; Aron and Aron 1996). In close relationships partners self-expand by enriching their identity via the identity of the other person (Aron and Aron 1996) and this process is rewarding, associated with excitement and positive affect (Aron et al. 2013). In their study assessing self-expansion in romantic relationships, Lewandowski and Aron (2002) included questions such as: "How much has being with your partner resulted in your learning new things," "How much has knowing your partner made you a better person," and "How much do you feel that you have a larger perspective on things because of your partner." Self-expansion in close relationships may take forms such as acquiring new knowledge and skills, enhancing self-respect, gaining new experiences, accomplishing new things and gaining greater awareness (Lewandowski and Aron 2002).

\section{Self-other inclusion in close relationships}

The construct of self-other inclusion in the context of close relationships describes the extent to which the cognitive construct of one's self overlaps with the cognitive construct of the other (Aron et al. 2013). Self-other inclusion entails an overlap of identities between two people where one perceives the other as part of one's self. Partners characterized by strong self-other inclusion share common opinions, perspectives and personality traits and have a similar sense of self. When there is strong self-other inclusion, one perceives the other's outcomes in life, whether positive or negative, as one's own (Aron et al. 1992; Aron and Aron 1996). In self-expansive close relationships, partners utilize each other's resources to enrich their personality, skills, knowledge and status, and by taking on parts of the identity of the other person they extend and enrich their self-concept (Aron et al. 2013; Aron et al. 1992). An individual may experience strong self-other inclusion when he or she spends a lot of time together with another person, share different activities and influence each other's decisions, activities and plans (Aron et al. 2013). Further, sharing of novel and exciting experiences (e.g., traveling) has also been found to reignite self-expansion in established close relationships (Aron et al. 2000). Self-expansion in close relationships may improve relationship quality and satisfaction (Lewandowski and Ackerman 2006).

\section{Self-expansion theory of close relationships and other theories of relationships}

Social exchange theory posits that individuals are driven to seek relationships that provide maximum benefits with minimum costs. Before entering relationships, individuals make assessments of possible benefits and costs (Homans 1958; Zafirovski 2005). Self-expansion theory offers clarifications with regard to the types of benefits individuals seek in relationships. Social exchange theory posits that intimate relationships with greater benefits than costs are more enduring (Homans 1958; Zafirovski 2005), and self-expansion theory, meanwhile, clarifies that self-expansion benefits keep individuals interested and committed in relationships (Aron et al. 2013).

Self-expansion theory in close relationships bears some similarities to social identity theory as both theories describe a process of merging of identities within groups or interpersonal relationships. However, whereas social identity theory examines individuals' motivation for belonging in groups, self-expansion theory examines the need for personal growth via close relationships (Hogg et al. 1995). Social identity theory posits that individuals are attracted to groups who share similar values and are driven to conform to the behaviors and beliefs of group members in order to gain a sense of belonging and safety (Hogg and Hardie 1991). Self-expansion theory examines the need for personal growth, where individuals are primarily attracted to different others who offer valuable opportunities to enrich one's identity, resources, skills and perspectives (Aron et al. 2013).

\section{Self-expansion theory of close relationships and brands}

As with human relationships, consumers develop affinity and connection to brands, forming close relationships 
with brands that provide opportunities for personal growth (Wang 2002). A study by Reinman et al. (2012) shows that similar to human relationships, self-expansion in close brand-consumer relationships may occur via inclusion of the brand in the self. Consumers incorporate as part of their identity, the resources, personality, symbolism and social status of their favorite brands (Kerviler and Rodriguez 2019; Reinman et al. 2012). For instance, loyal users of Apple identify with the brand's values of creativity and innovation and may adopt behaviors associated with these values when using the brand in their everyday lives. Consumers may also self-expand via unique and exciting experiences offered by brands (Reinman and Aron 2009). A study by Kerviler and Rodriguez (2019) found that luxury brands may enable self-expansion more than non-luxury brands as they offer more rich and intense experiences (Kerviler and Rodriguez 2019).

\section{Self-page inclusion and self-expansion in user-brand page close relationships}

Social media sites may be used as means for self-expansion as they provide opportunities for relationships, learning and experiences (Heinonen 2011). Social media activities such as tagging one's partner in status updates may enhance self-other inclusion and facilitate self-expansion in the context of romantic relationships (Carpenter and Spottswood 2013). Users interact with brand-related content on social media in order to express ideal aspects of their identity and extend their self-concept (Hollenbeck and Kaikati 2012). Social media brand pages also provide opportunities for growth via stimulation, excitement, learning and information.

Personal growth motivations have been found to drive sharing and creation activities but to a lesser extent than motivations relating to conservation and self-enhancement (Nikolinakou and Phua 2020). Applying self-expansion theory of close relationships, which posits that self-expansion occurs in close interpersonal or consumer-brand relationships (Aron et al. 2013; Reinman et al. 2012), we propose that users will use for self-expansion purposes, the brand pages with which they have a strong connection. Further, we posit that self-expansion occurs via self-page inclusion. Users self-expand by including their favorite page's perspectives, identities and resources in their sense of self. They may be motivated to adopt aspects of the brand identity personified through their favorite brand pages in order to expand their knowledge, skills and personality and gain new experiences. Thus,

H1 Self-page inclusion will have a positive effect on brand page self-expansion.

\section{Brand page flow and self-expansion}

Flow can be described as an emotional and physiological state where one is completely absorbed in an intrinsically motivating activity. While in a state of flow, individuals are motivated by the activity itself rather than the outcome (Csikszentmihalyi 1990). Flow involves focused attention and concentration, a sense of control on the activity, as well as loss of awareness of time and consciousness of one's self (Csikszentmihalyi 2014). It is an emotional and physiological state associated with positive affect, excitement, rejuvenation and immersion and experienced during activities that challenge one's skills, perceptions and understanding (Graham 2008; Csikszentmihalyi 2014). As flow involves challenge and intrinsic motivation, it leads to development of skills and, thus, results in self-expansion and personal growth (Graham 2008).

In computer-mediated environments, flow has been found to denote users' engagement with online platforms (Kwak et al. 2014). Skadberga and Kimmel (2004) show that visitors of websites that experience flow learn more information and are more likely to revisit the website. Social media users who experience flow on social media sites tend to spend more time and visit these sites more often (Pelet et al. 2017). Flow experienced during interaction with brand pages may act as a driving force that keeps the consumer engaged in the specific environment. Given that flow may lead to selfexpansion and personal growth (Csikszentmihalyi 2014; Graham 2008), we propose that social media users who experience flow during engagement with brand pages will also experience self-expansion.

H2 Brand page flow will have a positive effect on brand page self-expansion.

\section{Brand-related engagement: creation and sharing activities}

\section{The impact of page self-expansion and attachment on brand-related engagement}

Self-expansion in close relationships results in a sense of oneness involving a reciprocal sharing of resources between partners. Partners share and mutually invest their intellectual, emotional and social resources (Aron and Aron 1996). Attachment to brand pages may be defined by connection and prominence (Kleine-Kalmer 2015; Park et al. 2010). Connection refers to the emotional bond that users share with a brand page. Prominence pertains to the extent to which a brand page is prominent in consumers' minds and the extent to which they associate the brand page with social media sites in their 
memory. Whereas attachment delineates the strength of the relationship bond with a brand page, self-expansion refers to the degree to which the relationship provides opportunities and stimuli for personal growth (Aron and Aron 1996). In self-expansive relationships, individuals experience excitement and are motivated to grow closer in order to exchange valuable resources. As a close relationship becomes more established, self-expansion through the relationship diminishes. In established close relationships partners may experience attachment but not necessarily make effort to invest resources on the other partner for self-expansion purposes (Aron et al. 2000). Further, motivation for self-expansion may differ based on individuals' attachment style. Individuals with a secure attachment style, i.e., those who hold a positive self-image and have a positive stance toward relationships, may be more likely to seek self-expansion from intimate relationships, whereas individuals with avoidant attachment style, i.e., those who tend to be less trusting in relationships, may be less likely to seek self-expansion from their intimate relationships (Aron and Aron 2006).

Park et al. (2010) found brand attachment to be a more significant driver than positive brand attitude on consumer-engagement activities, such as promoting the brand, waiting to buy the brand instead of purchasing an alternative and defending the brand when others speak negatively of it. Strength of attachment to a brand page may also positively influence brand-related engagement on social media (Kleine-Kalmer 2015; Zaglia 2013). We propose that brand page self-expansion is more important than brand page attachment in motivating demanding social media activities, such as brand-related sharing and content creation. According to social exchange theory, individuals are motivated to maintain relationships when benefits derived from these relationships outweigh their costs. Further, they are motivated to invest more effort in relationships that provide valuable rewards and help them achieve personal goals (Homans 1958; Zafirovski 2005). Thus, in the context of social exchange theory, users may be more motivated by self-expansion than attachment to engage in demanding social media activities, as receiving valuable resources for self-expansion by the brand page may drive them more to invest in the relationship with the page. We propose that the more consumers perceive they can gain resources and opportunities to self-expand from brand pages, the more likely they are to reciprocate by investing their own resources. They may therefore engage in more demanding social media activities that require energy and resources, such as sharing or creating content.

Sharing brand-related content involves contribution of social resources. When consumers share content from a brand page on their social media profiles, they publicly endorse the brand and adopt the identity of the brand as part of their own identity on social media (Hollenbeck and Kaikati 2012; Muntiga 2011). Creation activities such as uploading photos, videos, posts and writing reviews for brands are also demanding social media activities since they require a greater investment of time, effort and creativity in comparison to more passive activities, such as browsing content.

H3 Brand page self-expansion will have a positive effect on (a) sharing and (b) creation activities.

H4 Brand page attachment will have a positive effect on (a) sharing and (b) creation activities.

\section{The impact of self-page inclusion on brand-related engagement}

In close relationships where there is strong self-other inclusion, individuals perceive the other as part of themselves. Therefore, they are less likely to act selfishly and are more driven to take actions that benefit the relationship. Partners are motivated to benefit the other as the other's positive outcomes are perceived as one's own (Aron et al. 2013; Aron, Aron and Smollan 1992). Similarly, in relation to brand pages we suggest that strong self-page inclusion would lead brand page fans to take valuable actions that benefit their favorite brand page, such as sharing and creating content, as well as writing reviews. We further hypothesize that self-page inclusion will also influence sharing and creation activities via its effect on self-expansion (see H1). Thus,

H5 Self-page inclusion will have a positive effect on (a) sharing and (b) creation activities.

H6 Self-page inclusion will mediate the relationship between self-expansion and sharing and creation activities.

\section{The impact of flow on brand-related engagement}

Carlson et al. (2017b) found that social media brand pages which elicit flow may increase consumers' engagement with brands, motivating valuable behaviors such as reviews and recommendations. Studies show that flow is an important ascendant of creativity and problem solving (e.g., Cseh et al. 2015; Csikszentmihalyi 2014). As a highly motivating and rewarding emotional and physiological state of intense concentration, flow has been found to enable creativity by eliciting positive affect and perseverance (Cseh et al. 2015). Flow entails loss of self-consciousness where the individual is not focused on thoughts and feelings about the self but completely immersed in a task. Thus, flow reduces 
self-censorship, fear of failure and social inhibitions (Csikszentmihalyi 2014; Dietrich 2004). While in a state of flow, one is less susceptible to be inhibited by criticism and becomes more courageous and spontaneous in taking action, expressing oneself, making novel connections and being creative. Further, flow is an implicit state where individuals operate spontaneously without conscious thinking (Dietrich 2004). We suggest that although self-expansion and self-page inclusion may motivate an individual toward sharing and creation activities to acquire benefits from their relationship with the brand page, flow will implicitly drive self-expression, action and creation in relation to brand pages. Further, flow experience in a social context may enhance individuals' sense of belonging and identification with the group and activate intentions to be of service and contribute to the welfare of the group (Páez et al. 2015). Thus, the experience of flow in brand pages may motivate users to share or create content in order to benefit the brand and its social media community. Further, we also hypothesize that flow will influence sharing and creation activities via its effect on self-expansion (H2).

H7 Brand page flow will have a positive effect on (a) sharing and (b) creation activities.

H8 Brand page flow will mediate the relationship between self-expansion and sharing and creation activities.

\section{Brand page experiences}

According to Brakus et al. (2009), brand experiences can be described as sensory, affective, behavioral and intellectual responses to brand stimuli in the form of design, packaging, promotions, advertising and services. Experiences offered by brands be important for enhancing customer affinity and loyalty (Brakus et al. 2009; Nysveen et al. 2013). Further, intellectual, sensorial and emotional experiences by luxury brands have been found to lead to self-expansion (Kerviler and Rodriguez 2019).

Social media brand pages are media-rich environments providing opportunities for engaging experiences. Consumers visit and interact with brand pages not only for functional reasons, such as information and promotions, but also for needs relating to hedonism and entertainment, stimulation, social interaction and self-enhancement (Muntiga et al. 2011; Nikolinakou and Phua 2020). With the use of images, text, videos as well as interactivity and synchronicity, brand pages deliver diverse messages in impactful formats to consumers (Ashley and Tuten 2015; Kim et al. 2015). Brands can engage consumers via stories, celebrities, events and user-generated content (content created by consumers for brands) (Tafesse 2016).
Research by Tafesse (2016) shows that experiences offered by brand pages may drive consumers' engagement on social media. Further, the experience value of brand pages may influence consumers' intention to remain engaged with brand pages. Carslon et al. (2017a) also found that brand page experiences deliver functional value (information and resources), emotional value, socialization value (interactions with similar others), innovativeness/novelty (uniqueness of content) and relationship value (the effort the brand page makes to maintain the loyalty of its fans). In this study we examine how types of brand page experiences may influence flow, self-expansion and self-other inclusion. We specifically consider the following types of experiences relevant to brands and social media pages: emotional (e.g., the page elicits feelings and emotions), sensory (e.g., the page is sensory pleasing), intellectual (e.g., the page encourages learning), behavioral (e.g., the page prompts users to visit the website), entertaining (e.g., using the page is fun), innovativeness/ novelty (e.g., the page offers a unique experience), social (e.g., the page encourages interaction with similar people), relationships (e.g., brand page is interesting in maintaining connections with users) and functional (e.g., brand page is a useful resource, there is useful information on this page) (Brakus et al. 2009; Carlson et al. 2017a; Kerviler and Rodriguez 2019).

\section{The effect of brand page experiences on self-expansion}

Aron et al. (2000) show that sharing of novel and interesting experiences is most important for self-expansion in long-term relationships. Self-expansion takes place to the extent that the relationship offers new resources enabling partners to grow. Relationships that no longer offer novelty cease to be self-expanding (Mattingly and Lewandowski 2014a). Novel and interesting experiences are also important for individual self-expansion outside of relationships (Mattingly and Lewandowski 2013). Novel and interesting experiences (e.g., traveling, learning new skills, creating a business together) are important for self-expansion as such experiences challenge partners to evolve by enabling them to gain new perspectives, develop new capabilities and use new resources to cope with stimulating situations. Knowledge that individuals acquire through such experiences help them expand their self-concept (Mattingly and Lewandowski 2014b). Therefore, in the context of their brand page-user relationships, we expect that novel and unique experiences that help users learn new things would be more important for self-expansion than other types of experiences offered on brand pages (emotions, senses, social, information, behavioral, entertainment, relationships and functional). Thus, 
H9 Brand page experiences related to innovativeness/novelty and learning (intellectual) will have a stronger positive effect on brand page self-expansion, compared to other types of brand page experiences (emotional, sensory, behavioral, entertaining, social, relationships, functional).

\section{The effect of brand page experiences on page flow}

Further, we propose that social and emotional experiences will mostly drive flow on social media brand pages. Social interactions may enable flow in social media environments (Carlson et al. 2017b; Kaur et al. 2016). Walker (2010) found that in highly interactive social situations involving intense collaboration, common goals and group identification (e.g., sports, playing jazz, a very engaging conversation), individuals may experience collective flow. Collective flow involves shared intense absorption with the group task, high attention to group members, loss of awareness of self and emotional contagion, a collective state that involves sharing of emotions. Flow experienced in a social context may strengthen social integration and boost individuals' self-esteem (Páez et al. 2015). Social presence or social interactivity on social media brand pages also contributes to users' flow experience (Carlson et al. 2017b; Kaur et al. 2016). Participation in social media is inherently about social connection and relationships (Ellison et al. 2007). Within social media platforms, brand pages serve as communities where users connect via their interest toward brands (Phua et al. 2017). Active engagement behaviors on brand pages encompass social interaction (Ashley and Tuten 2015; Schivinski et al. 2016). Users show active engagement with a brand page when they interact with the brand page as if it was a person (liking and sharing its content): They relate to influencers, exchange opinions and comments with other users and collaborate with the brand to create content (Ashley and Tuten 2015; Schivinski et al. 2016). Therefore, we expect that users' experience of flow on brand pages emanates from the quality of social interactions occurring on brand pages.

Emotional arousal and positive affect have been found to be key components of the experience of flow (Cseh et al. 2015; Csikszentmihalyi 2014). Further, sharing of intense positive emotions within groups can elicit emotional contagion and collective flow (Páez et al. 2015). Emotions may drive brand page engagement: Users engage with brandrelated content on social media platforms that elicits strong emotions (Araujo et al. 2015; Yuki 2015). We suggest that the extent to which a brand pages offers emotional experiences will positively influence flow. Thus,
H10 Brand page experiences related to social and emotional experiences will have a stronger positive effect on brand page flow, compared to other types of brand page experiences (sensory, behavioral, entertaining, relationships, functional, intellectual, innovativeness/novelty).

\section{The effect of brand page experiences on self-page inclusion}

Closeness in relationships encompasses sharing of perspectives, viewpoints, experiences in life and outcomes. Inclusion of the other in the self leads to a common shared identity and a sense of oneness. Self-disclosure, interest in the other and shared participation in activities, may create a sense of intimacy, bringing partners closer together (Aron et al. 2013; Reis and Shaver 1988). In the context of brand pages, we suggest that the quality of social interactions a brand page offers and the interest the page demonstrates toward its fans will also enhance users' intimacy and sense of oneness with the brand page. Thus,

H11 Brand page experiences related to social and relationship experiences will have a stronger positive effect on self-page inclusion, compared to other types of brand page experiences (sensory, behavioral, entertaining, relationships, functional, intellectual, innovativeness/novelty).

\section{The effect of brand page experiences on page attachment}

Shared experiences and pleasure may bolster sense of attraction and positive affect in relationships leading to enhanced attachment. Consumers also tend to feel more connected to brands that offer opportunities for arousing and entertaining interactions and experiences (Park et al. 2010; Patwardhan and Balasubramanian 2011). Further, Kleine-Kalmer (2015) found that social media users experience a stronger attachment to brand pages that offer opportunities for social interactions and entertainment. Thus,

H12 Brand page experiences related to social and entertainment experiences will have a stronger positive effect on brand page attachment, compared to other types of brand page experiences (sensory, behavioral, emotions, relationships, functional, intellectual, innovativeness/novelty).

Fig. 1 shows the conceptual model and the expected relationships between or among the variables included in this study. 


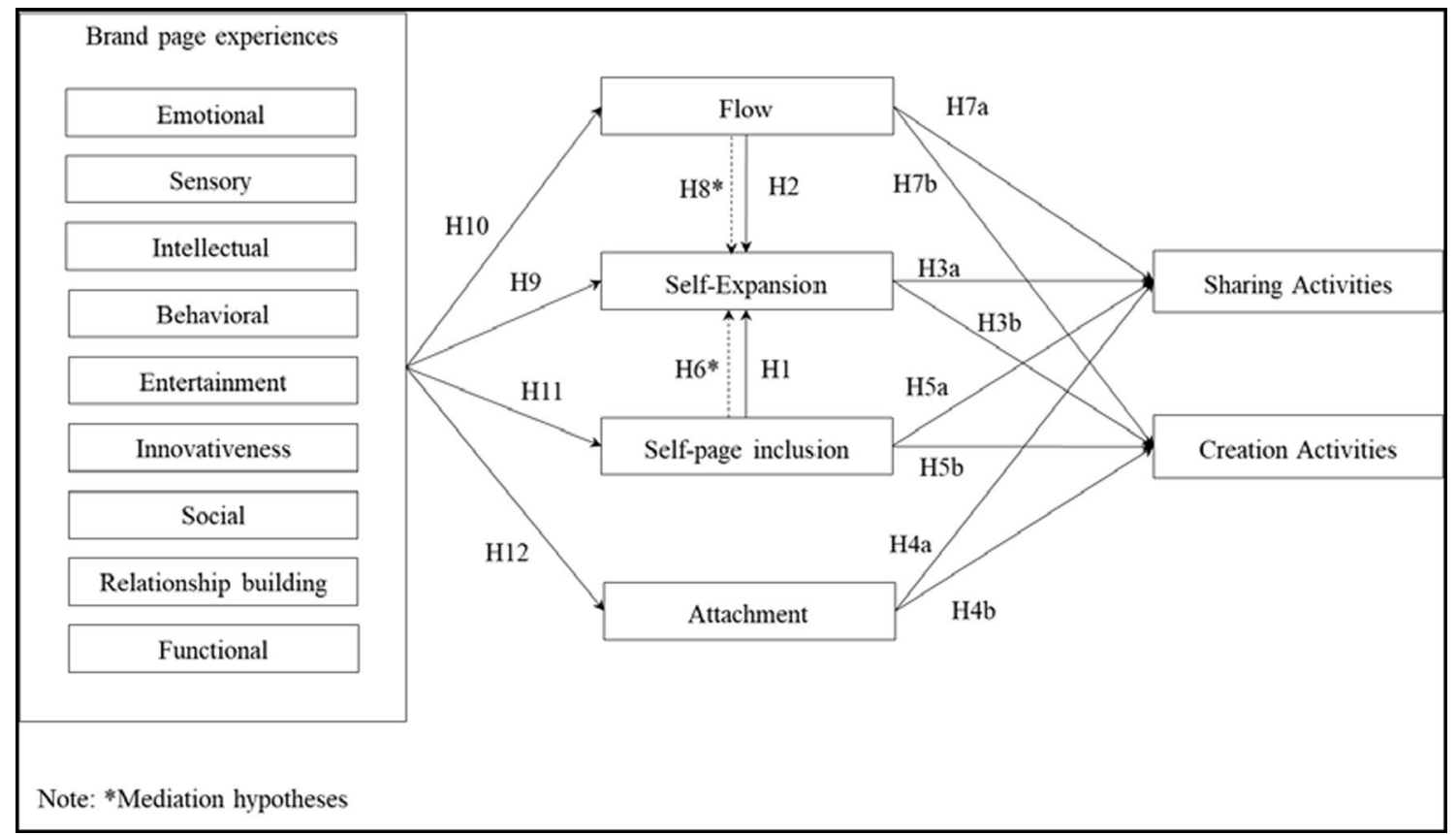

Fig. 1 Conceptual model

\section{Method}

An online survey was conducted with members $(N=238)$ of Amazon Mechanical Turk. Participants were 18 to 34 years of age, lived in the USA and had a favorite brand page on Instagram. The sample consisted of loyal page fans rather than loyal brand users as studies suggest that the profile of brand page fans is not necessarily the same as the profile of brand fans (Lipsman et al. 2012). Although brand affiliation may drive users to become followers/fans of a brand page (Yllmaz and Enginkaya 2015), loyalty of fans to brand pages is not only driven by their usage or relationship with the brand but also depends on the quality of the experiences offered on the brand page (Kleine-Kalmer 2015). Instagram was selected for this study as it is the second most frequently used social media platform among millennials in the USA (Pew Research Center 2019). Instagram differs from other social media sites as a predominantly photo- and video-sharing platform used for visual storytelling by users and brands (Social Media Today 2019). Instagram offers a variety of visual features to engage its users, including stories, filters and Instagram TV videos. Consumers may experience more commitment and engagement with brand pages on Instagram compared to other social media platforms (e.g., Twitter or Facebook) as interactions with brands on Instagram are driven more by creativity and emotions (Phua et al. 2017).

\section{Procedure}

Participants were recruited via an advertisement on M-Turk. Only high-quality participants, with approval rate over $90 \%$ were selected for the study. The survey was conducted via an online questionnaire on Qualtrics. At the beginning of the questionnaire, participants were asked filter questions about their usage of Instagram and their interactions with brand pages on Instagram. Only participants between the ages of 18 and 34 who visited Instagram more than 2-3 times a week and followed brands were selected. Additionally, users had to have a "favorite brand page" on Instagram (with which they interact with the most compared to other brand pages). Participants were asked to choose their favorite brand page from a list of 100 brands popular among millennial consumers or state a favorite brand page outside this list (Cohen and Flores 2020). They were then directed to access their favorite Instagram brand page and browse its content for five minutes. An attention-check question followed whereby respondents were asked to describe the most interesting content they saw on the brand page. Next, participants were asked a series of questions with regard to their favorite Instagram brand page. First, they rated the level of closeness they experience with the brand page. In order to measure self-page closeness, we adapted the Inclusion of Other in the Self scale (Fig. 2) (Aron et al. 1992). 
Fig. 2 Measurement of selfpage inclusion. Based on Aron, Aron and Smollan (1992), The Inclusion of Other in the Self (IOS) scale

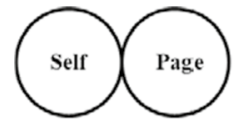

1.

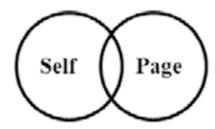

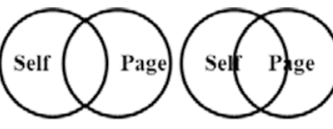

3.

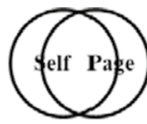

5.

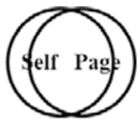

6.

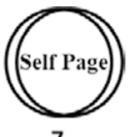

7.

Based on Aron, Aron and Smollan (1992), The Inclusion of Other in the Self (IOS) Scale

Participants then reported the extent to which they experience flow and self-expansion in relation to their favorite brand page on 7-point Likert scales. They rated the extent to which they feel they gain different experiences from their favorite brand page and level of attachment to their favorite brand page (7-point Likert scales). The experiences assessed were: emotional, sensory, intellectual, behavioral, entertaining, innovativeness/novelty, social, relationships and functional (Brakus et al. 2009; Carlson et al. 2017a; Kerviler and Rodriguez 2019). The measures used for flow, self-expansion, attachment and brand page experiences are described in Tables 1 and 2. At the end of the questionnaire, participants were asked how willing they were to share different types of content related to their brand page (information, ads or stories, promotions, reviews) as well as their intention to create content for their brand page (videos, photos and posts) and write product reviews (Nikolinakou and Phua 2020). Measures of brand sharing and brand creation are shown in Table 3. The order of statements for all the above questions was rotated.

\section{Results}

\section{Sample}

The sample consisted of 238 participants, with no incomplete responses. This sample size was deemed adequate for this study for the following reasons. First, it is recommended to have at least 200 samples for a structural equation model

Table 1 Page flow, self-expansion and attachment in relation to brand pages—measures, Cronbach's alpha and means

\begin{tabular}{|c|c|c|c|}
\hline Measure & Items & Cronbach's alpha & Means \\
\hline $\begin{array}{l}\text { Flow } \\
\text { (Sources: Kaur et al. 2016; Skadberg and Kimmelb 2004) }\end{array}$ & $\begin{array}{l}\text { I forget about my immediate surroundings when I use the } \\
\text { brand page } \\
\text { I forget everything when I use the brand page } \\
\text { When using the brand page, I never think about other } \\
\text { things } \\
\text { Using this brand page keeps me happy throughout the } \\
\text { day }\end{array}$ & $\alpha=.86$ & 4.99 \\
\hline $\begin{array}{l}\text { Self-expansion } \\
\text { (Sources: Lewandowski and Aron 2002; Kerviler and } \\
\text { Rodriguez 2019) }\end{array}$ & $\begin{array}{l}\text { I feel I gain new experiences when I participate on this } \\
\text { brand page } \\
\text { I feel I gain exciting experiences when I participate on } \\
\text { this brand page } \\
\text { I feel that I learn new things when I participate on this } \\
\text { brand page } \\
\text { I feel that I increase in my ability to accomplish new } \\
\text { things when I participate on this brand page } \\
\text { Participating on this brand page gives me a greater } \\
\text { awareness of things } \\
\text { Participating on this brand page gives a larger perspec- } \\
\text { tive on things } \\
\text { Participating on this brand page helps me expand my } \\
\text { sense of the kind of person I am } \\
\text { Participating on this brand helps me add positive quali- } \\
\text { ties to my sense of self }\end{array}$ & $\alpha=.92$ & 5.39 \\
\hline $\begin{array}{l}\text { Attachment } \\
\text { (Sources: Park et al. 2010) }\end{array}$ & $\begin{array}{l}\text { The brand page is a part of me and who I am } \\
\text { I am personally connected to this brand } \\
\text { My thoughts and feelings toward this brand page are } \\
\text { often automatic, coming to mind seemingly on their } \\
\text { own } \\
\text { My thoughts and feelings toward this brand page come to } \\
\text { me naturally and instantly }\end{array}$ & $\alpha=.82$ & 5.45 \\
\hline $\begin{array}{l}\text { Self-page inclusion } \\
\text { (Sources: Aron et al. 1992) }\end{array}$ & Inclusion of the brand in the self one-item scale & & 4.82 \\
\hline
\end{tabular}


Table 2 Brand page experiences-measures, Cronbach's alpha and means

\begin{tabular}{|c|c|c|}
\hline Measure & Items & Means \\
\hline $\begin{array}{l}\text { Emotional ( } \alpha=.85 \text { ) } \\
\text { (Kerviler and Rodriguez 2019) }\end{array}$ & $\begin{array}{l}\text { This brand page is emotional } \\
\text { I have emotions for this brand page } \\
\text { This brand page induces my feelings and sentiments }\end{array}$ & 5.17 \\
\hline $\begin{array}{l}\text { Sensory }(\alpha=.79) \\
\text { (Kerviler and Rodriguez 2019) }\end{array}$ & $\begin{array}{l}\text { This brand page appeals to my senses } \\
\text { This brand page makes an impression on at least one of my senses: smell, sound, sight, taste, and } \\
\text { touch } \\
\text { I find this brand page interesting in a sensory way }\end{array}$ & 5.60 \\
\hline $\begin{array}{l}\text { Intellectual ( } \alpha=.79) \\
\text { (Kerviler and Rodriguez 2019) }\end{array}$ & $\begin{array}{l}\text { This brand page invites me to discover new things } \\
\text { This brand page encourages my learning } \\
\text { I had the desire to advance my knowledge with this brand page }\end{array}$ & 5.55 \\
\hline $\begin{array}{l}\text { Behavioral }(\alpha=.79) \\
\text { (Brakus et al. 2009) }\end{array}$ & $\begin{array}{l}\text { The brand page prompts me to take action on the brand page (e.g., click on links, search information, } \\
\text { watch videos, click on photos, etc.) } \\
\text { The brand page prompts me to visit the brand website } \\
\text { The brand page prompts me to further search content and information }\end{array}$ & 5.55 \\
\hline $\begin{array}{l}\text { Entertainment }(\alpha=.71) \\
\text { (Carlson et al. 2017a) }\end{array}$ & $\begin{array}{l}\text { The brand page doesn't just sell products-it entertains me } \\
\text { I think the brand page is very enjoyable } \\
\text { I have fun when I use the brand page }\end{array}$ & 5.69 \\
\hline $\begin{array}{l}\text { Innovativeness/novelty }(\alpha=.83) \\
\text { (Carlson et al. 2017a) }\end{array}$ & $\begin{array}{l}\text { The brand page content is highly innovative compared to others that I have seen } \\
\text { The brand page delivers an innovative experience } \\
\text { The brand page offers a unique experience and is different from other brand pages }\end{array}$ & 5.48 \\
\hline $\begin{array}{l}\text { Social }(\alpha=.79) \\
\text { (Carlson et al. 2017a) }\end{array}$ & $\begin{array}{l}\text { I find out about people like me on this brand page } \\
\text { I interact with people like me on this brand page } \\
\text { I meet people like me on this brand page }\end{array}$ & 5.26 \\
\hline $\begin{array}{l}\text { Relationship building }(\alpha=.79) \\
\text { (Carlson et al. 2017a) }\end{array}$ & $\begin{array}{l}\text { The brand page is committed to maintaining long-term relationships with me } \\
\text { The brand page is interested in having a connection with me } \\
\text { The brand page is committed to delivering add-in values (e.g., special offers, events, member pro- } \\
\text { grams) to keep me loyal with the brand }\end{array}$ & 5.44 \\
\hline $\begin{array}{l}\text { Functional }(\alpha=.81) \\
\text { (Carlson et al. 2017a) }\end{array}$ & $\begin{array}{l}\text { I find information on this brand page to be valuable } \\
\text { I think this brand page is a helpful resource } \\
\text { There is useful information on this brand page }\end{array}$ & 5.70 \\
\hline
\end{tabular}

Table 3 Sharing and creation activities—-measures, Cronbach's alpha and means

\begin{tabular}{ll}
\hline Measure & Items \\
\hline $\begin{array}{l}\text { Sharing activities }(\alpha=.93) \\
\text { (Source: Nikolinakou and Phua }\end{array}$ & $\begin{array}{l}\text { Share content that is informational (e.g., news, launch of new products/services, innovations, } \\
\text { infographics) related to this brand page }\end{array}$ \\
2020; Schivinski et al. 2016) & $\begin{array}{l}\text { Share promotions, coupons, contests, offers, events related to this brand page } \\
\text { Share advertisements, stories related to this brand page }\end{array}$ \\
& $\begin{array}{l}\text { Share my reviews, evaluations about products or services related to this brand page } \\
\text { Share other consumers' reviews, evaluations about products or services related to this brand page }\end{array}$ \\
& Write reviews or evaluations about a product or service related to this brand page \\
$\begin{array}{ll}\text { Creation activities }(\alpha=.88) \\
\text { (Source: Nikolinakou and Phua }\end{array}$ & Write (initiate) posts (photo, video, posts or stories) related to this brand page \\
2020; Schivinski et al. 2016) & \\
\hline
\end{tabular}

study and typical sample sizes in SEM studies range from 200 to 300 even though a larger sample size is needed for more complex models or when there are higher levels of missing data (Kline 2015). Second, the item-to-sample ratio was 1:4.7-close to 1:5 following the recommendations of Hair et al. (2018) and Bentler and Chou (1987) because several indicators were used and factor loadings were large. The variable-to-sample ratio was above 1:9 (except for 1 variable which had 2 indicators, the rest of the variables had at least
3 indicators [at least 1:14 ratio]). Third, communalities were examined, as previous studies indicated that the sample size is of less concern when communality is high (i.e., close to or greater than 0.50; e.g., Hogarty et al 2005; MacCallum et al. 1999). Average communality was 0.66 , with a range of 0.45 to 0.81 . Only 2 items were below 0.50 . Finally, larger sample sizes are necessary because of the possibility of low statistical power not able to detect significance and the concern over the low reliability to offset the potential distorting 
effects of measurement error (e.g., Kline 2015). However, as discussed below, percentages of variance explained by independent variables were high and effect sizes between variables ranged from no significant relationship to strong relationship. Considering all these evaluation criteria, the sample size in our study is not a concern.

The ages of the participants ranged from 18 to $34: 10.9 \%$ of the sample were $18-24$ years of age, $44.5 \%$ were $25-29$, and $44.5 \%$ were $30-34$. Regarding ethnicity, $75.2 \%$ were White, $17.2 \%$ were Black or African American, $2.9 \%$ were Asian or Asian-American, 2.5\% were Native American or Native Alaskan, and $1.4 \%$ were other ethnicities. With regard to employment, $88.2 \%$ were employed full-time, $8.8 \%$ were employed part-time, $1.3 \%$ were unemployed and $1.7 \%$ were students. For education: $61.3 \%$ had a college degree, $15.5 \%$ had some college, $11.8 \%$ had a postgraduate degree, $3.4 \%$ had a high school degree and $0.4 \%$ less than high school. For marital status: $60.1 \%$ were married, $26.9 \%$ never mar$\mathrm{ried} / \mathrm{single}, 10.9 \%$ living with partner, and $3.1 \%$ separated or divorced. Fifty-eight (58\%) of participants visited Instagram several times a day, 15\% visited Instagram twice a day, $13 \%$ visited Instagram once a day, and $14 \%$ of participants visited Instagram 4 to 6 times a week.

\section{Preliminary analyses: means}

On average, participants reported that they experienced brand page self-expansion, flow, attachment and self-page inclusion in relation to their favorite brand pages, above the midpoint (4) of the 7-point Likert scale (Tables 1 and 3). Cronbach's alpha for self-expansion, flow, attachment, sharing and creation activities were at acceptable levels (Hair et al. 2018, p. 760) and are reported in Tables 1 and
3. Participants also reported that they gained experiences related to entertainment, innovativeness/novelty, relationships, intellectual stimulation, behaviors, emotions, sociability, functionality and sensory needs from their favorite brand page (Table 2). The reported means for the brand page experience measures were five or above on a 7-point Likert scale. Cronbach's alpha for all brand page experiences were at acceptable levels (Hair et al. 2018, p. 760) and are reported in Table 2 .

\section{Preliminary analyses: correlations}

A preliminary analysis of correlation using SPSS 26 was performed among the all variables included in this study. Table 4 illustrates correlational relationships among the variables (Table 4).

AMOS 26 was used to perform a Structural Equation Model (SEM) analysis to test hypotheses proposed in this study. We calculated composite scores for these variables and conducted the analysis. The model fit indices such as chi-square $\left(\chi^{2}\right) / d f$, CFI, IFI, TLI, RMSEA and SRMR are examined following the recommendation of Byrne (2010) and $\mathrm{Hu}$ and Bentler $(1998,1999)$. Criteria of SRMR $(<0.08)$ supplemented with CFI $(\geq 0.95)$ and IFI $(=$ BL89 $\geq 0.95)$ were used (Hu and Bentler 1999). Because TLI and RMSEA tend to over reject the models at small sample size (e.g., $N<250$; Hu and Bentler 1999), the cut-off values of greater than 0.90 for TLI (Bentler and Bonett 1980) and lower than 0.10 for RMSEA (MacCallum et al. 1999) were considered. Even though there is no consensus regarding an acceptable ratio for relative or normed chi-square $\left(\chi^{2} / d f\right.$; Kline 2015), the cutoff value of lower than 5 is used (Schumacker and Lomax 2004). The fit indices were satisfactory: $\chi^{2}$

Table 4 Correlation among variables

\begin{tabular}{llllllllllllllll}
\hline & 1 & 2 & 3 & 4 & 5 & 6 & 7 & 8 & 9 & 10 & 11 & 12 & 13 & 14 & 15 \\
\hline 1. Sensory & 1 & & & & & & & & & & & & \\
2. Entertainment & 0.692 & 1 & & & & & & & & & & & \\
3. Novelty & 0.593 & 0.678 & 1 & & & & & & & & & & \\
4. Relationship & 0.549 & 0.561 & 0.727 & 1 & & & & & & & & & \\
5. Functional & 0.602 & 0.665 & 0.621 & 0.617 & 1 & & & & & & & & & \\
6. Intellectual & 0.569 & 0.632 & 0.65 & 0.709 & 0.742 & 1 & & & & & & & \\
7. Behavioral & 0.533 & 0.575 & 0.505 & 0.569 & 0.578 & 0.612 & 1 & & & & & & \\
8. Social & 0.450 & 0.520 & 0.568 & 0.595 & 0.499 & 0.599 & 0.441 & 1 & & & & \\
9. Emotional & 0.448 & 0.457 & 0.555 & 0.543 & 0.514 & 0.619 & 0.430 & 0.647 & 1 & & & & & \\
10. Self-page inclusion & 0.292 & 0.365 & 0.431 & 0.478 & 0.355 & 0.392 & 0.299 & 0.464 & 0.385 & 1 & & & & \\
11. Brand page flow & 0.320 & 0.367 & 0.494 & 0.500 & 0.355 & 0.467 & 0.354 & 0.659 & 0.569 & 0.499 & 1 & & \\
12. Attachment & 0.639 & 0.720 & 0.710 & 0.684 & 0.726 & 0.757 & 0.59 & 0.681 & 0.634 & 0.458 & 0.550 & 1 \\
13. Self-expansion & 0.540 & 0.609 & 0.748 & 0.732 & 0.698 & 0.792 & 0.570 & 0.703 & 0.683 & 0.504 & 0.577 & 0.810 & 1 \\
14. Creation activities & 0.327 & 0.373 & 0.497 & 0.539 & 0.424 & 0.537 & 0.439 & 0.641 & 0.591 & 0.488 & 0.617 & 0.569 & 0.625 & 1 \\
15. Sharing activities & 0.363 & 0.402 & 0.53 & 0.595 & 0.466 & 0.568 & 0.435 & 0.650 & 0.608 & 0.469 & 0.605 & 0.629 & 0.674 & 0.883 & 1 \\
\hline
\end{tabular}




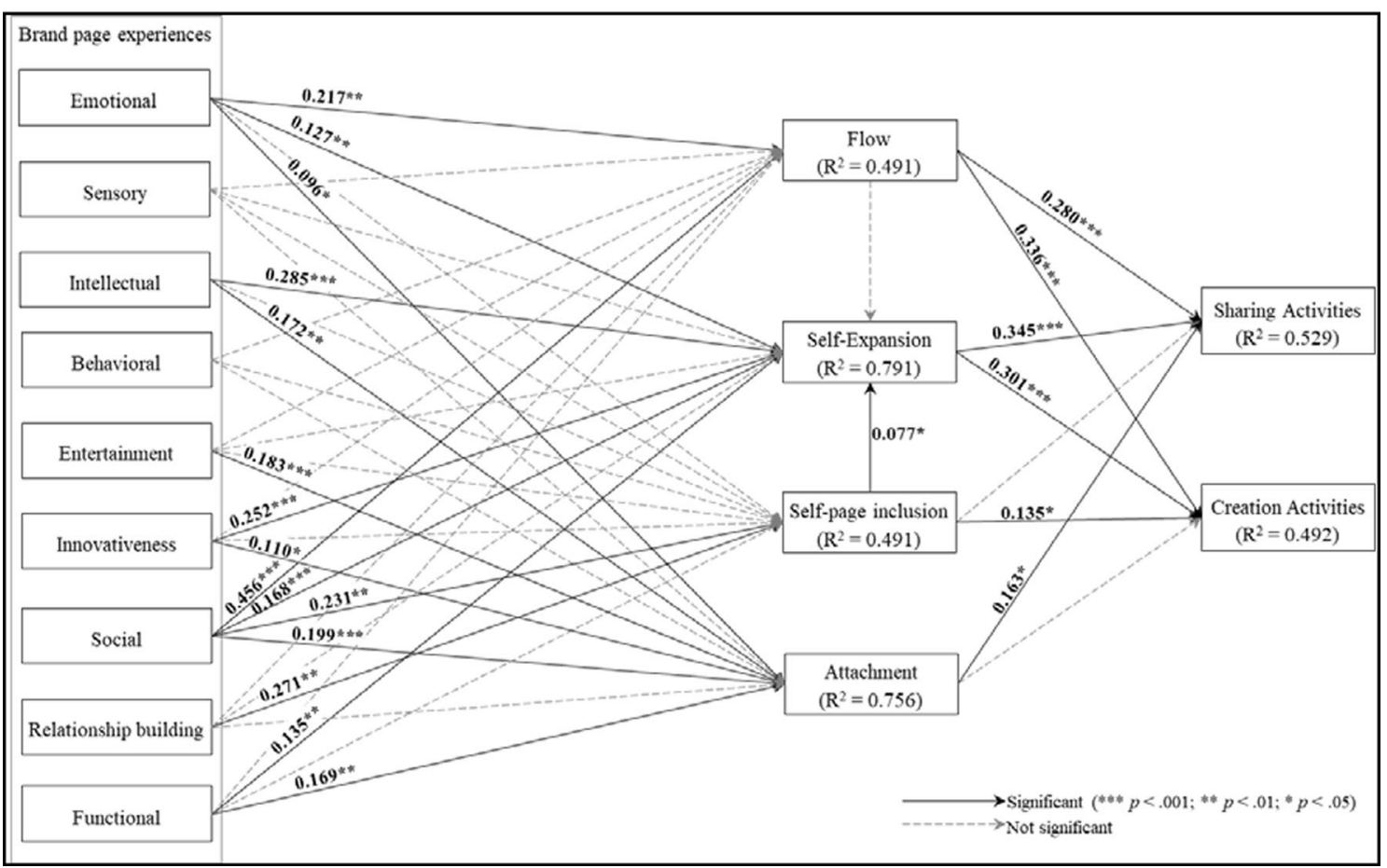

Fig. 3 Structural equation model (SEM) analysis

$(72.598) / d f(22)=3.3 ; \mathrm{CFI}=0.982 ; \mathrm{IFI}=0.983 ; \mathrm{TLI}=0.916$; RMSEA $=0.099 ;$ SRMR $=0.026$. Multicollinearity was at good levels as VIF was smaller than 4 and tolerance was larger than 0.20, given that tolerance must be larger than the threshold of 0.10 and VIF must be lower than the threshold of 10 (Hair et al. 2018, p. 316).

\section{H1-H2 effect of self-page inclusion and page flow on self-expansion}

Results for $\mathrm{H} 1$ and $\mathrm{H} 2$ are shown in Fig. 3. H1 predicted that self-page inclusion would positively influence selfexpansion. $\mathrm{H} 1$ is supported as self-page inclusion positively influenced self-expansion $(\beta=0.077, p<0.05)$. $\mathrm{H} 2$ predicted that brand page flow would have a positive effect on consumers' self-expansion. Flow did not significantly predict self-expansion $(\beta=0.034, p=0.416)$. Therefore, $\mathrm{H} 2$ is not supported.

\section{H3-H8: effects of self-expansion, self-page inclusion, page flow and page attachment on sharing and creation activities}

As shown in Fig. 3, self-expansion, self-page inclusion, flow and attachment explained $52.9 \%$ of variance for sharing activities and $49.2 \%$ for creation activities. Self-expansion had a positive effect on sharing $(\beta=0.345, p<0.001)$ and creation activities $(\beta=0.301, p<0.001)$. Therefore, $\mathrm{H} 3$ is supported. Attachment had a significant positive influence on sharing activities $(\beta=0.163, p<0.01)$, but its influence on creation activities was not significant $(\beta=0.085, p=0.227)$. Therefore, $\mathrm{H} 4$ is partially supported. Further, the influence of attachment on sharing activities was overall weaker than that of selfexpansion (for attachment: $\beta=0.163, p<0.01$ vs. $\beta=0.345$; for self-expansion: $p<0.001$ ).

Self-page inclusion positively influenced creation activities $(\beta=0.135, p<0.05)$ but not sharing activities $(\beta=0.086$, $p=0.098)$. Thus, $\mathrm{H} 5$ is partially supported. Self-page inclusion had a significant indirect effect on sharing activities via selfexpansion $(\beta=0.029, p=0.03)$. The direct effect of self-page inclusion on sharing activities was not significant $(\beta=0.086$, $p=0.098$ ). Self-page inclusion had a significant indirect effect on creation activities via self-expansion $(\beta=0.028, p=0.042)$ as well as a significant direct effect on creation activities ( $\beta=0.135, p=0.012)$. Thus, H6 is supported.

Page flow had a significant positive influence on sharing $(\beta=0.280, p<0.001)$ and creation $(\beta=0.336, p<0.001)$ activities. Thus, $\mathrm{H} 7$ is supported. The indirect effect of page flow on sharing $(\beta=0.011, p=0.375)$ and creation $(\beta=0.011$, $p=0.348)$ activities via self-expansion was not significant. Thus, H8 is not supported. 


\section{H9-H12: the effects of brand page experiences on self-expansion, self-page inclusion, page flow and page attachment}

H9 to H12 examined the influence of brand page experiences on self-expansion, self-page inclusion, flow and attachment. All of these hypotheses were supported. As shown in Fig. 3, brand page experiences measures explained $79.1 \%$ of variance of self-expansion, $49.1 \%$ of the variance of flow, $49.1 \%$ of variance of self-page inclusion and $75.6 \%$ of variance of attachment. Innovativeness/novelty $(\beta=0.252, p<0.001)$ and intellectual experiences $(\beta=0.285, p<0.001)$ had the strongest positive influence on self-expansion. Thus, H9 is supported. Social $(\beta=0.456, p<0.001)$ and emotional experiences $(\beta=0.217, p<0.01)$ had the strongest positive influence on flow. Thus, H10 is supported. Relationship $(\beta=0.271, p<0.01)$ and social $(\beta=0.231, p<0.01)$ experiences had the strongest positive influence on self-page inclusion. Thus, H1 1 is supported. Social $(\beta=0.199, p<0.001)$ and entertainment $(\beta=0.183, p<0.001)$ experiences had the strongest positive influence on attachment. Therefore, H12 is supported.

\section{Discussion}

\section{The impact of self-expansion on creation and sharing activities}

An important contribution of this research to the literature on social media branding is that self-expansion is an important motivation for loyal fans' engagement in meaningful activities, such as sharing and creation activities. Whereas previous studies have found that loyalty and level of attachment to brand pages (Kleine-Kalmer 2015; Zaglia 2013) may drive social media users' brand-related engagement activities, this research indicates that for users who have an established relationship with a brand page, self-expansion via the brand page is an important driver for brand-related sharing and creation activities on social media. Thus, the more social media users gain opportunities for personal growth from their favorite brand pages the more likely they are to share and create brand-related content.

Brands may offer opportunities for self-expansion on their brand pages by providing educational content and knowledge, by helping consumers cultivate their skills and interests and enabling them to expand their sense of awareness, broadening their perspectives and adding positive qualities to their sense of self. For example, food companies (e.g., Whole Foods) could post videos on social media with recipes for various types of cuisine or how to creatively use specific ingredients. Technology-based brands (e.g., General
Electric) could provide interesting content on technological innovations. Brands could also help users experience self-expansion by advocating on their social media pages for important causes and curating content relating to issues such as environmental conservation, social justice, equality, healthy living (emotionally and physically) and being kind to others. For example, companies such as REI advocate for spending time outdoors and highlight the mental and physical benefits of being close to nature.

Reinman et al. (2012) found that self-expansion via brands is achieved by self-brand inclusion. This research shows that self-page inclusion facilitates the process of selfexpansion via brand pages. The closer fans feel to a brand page and adopt the identities, perspectives and resources offered on the brand page, the stronger they experience selfexpansion. According to self-expansion theory, close interpersonal relationships must constantly offer opportunities for personal growth and keep the process of self-other inclusion in the relationship active in order to attain longevity (Aron et al. 2013). Similarly, brands on social media should constantly rejuvenate their pages and offer new perspectives, identities and resources to re-engage consumers in self-page inclusion and motivate consumer interaction.

\section{The impact of self-page inclusion on sharing and creation activities}

Further, our findings suggest that self-page inclusion not only has an indirect impact on sharing and creation activities via self-expansion, but also a direct effect on creation activities. Thus, the more users integrate a brand page's identity in their self-concept, the more likely they are to create content (e.g., posts, videos, photos etc.) and write reviews for brands on social media. Individuals who include their partners' identity in their sense of self are motivated to benefit their partners, as their partners' positive outcomes are perceived as their own (Aron et al. 1992, 2013). Similarly, our findings suggest that when users include a brand page as part of their social media identity, they perceive that by promoting the page on social media they are also positively benefiting their own self-perceived identity on social media.

\section{The impact of self-expansion vs. page attachment on sharing/creation activities}

The findings of this study extend prior research on brand page engagement behaviors (Kleine-Kalmer 2015; Carlson et al. 2017a; Tafesse 2016) and clarify that for loyal fans of social media brand pages, self-expansion is a more important driver than brand page attachment for sharing and creation activities. Whereas attachment delineates the strength of the relationship bond with a brand page, self-expansion refers to the degree to which the relationship provides benefits and 
opportunities for personal development. Self-expansion may motivate greater reciprocation of resources between partners than attachment (Aron and Aron 1996). Therefore, in relation to brand pages, users who derive self-expansion value and benefits from a brand page are motivated to reciprocate and invest their resources to their favorite brand page. Social media users who have a self-expansive relationship with their favorite brand pages may be more willing to invest their resources to these brand pages, engaging in more demanding activities on the site, such as sharing and content creation.

\section{The impact of flow on sharing and creation activities}

Whereas self-expansion describes the motivation and benefits of personal growth (Aron and Aron 1996), flow describes an emotional and physiological state whereby one is completely absorbed in an intrinsically motivating activity (Csikszentmihalyi 1990). Further, previous research findings suggests that self-expansion may be a potential effect of flow states (Graham 2008). Brand page flow was found to be an important driver with direct effects on sharing and creation activities. As an implicit state, flow encourages effortless action, spontaneous self-expression and creativity, as individuals who experience flow are less likely to feel inhibited by internal or external criticism (Csikszentmihalyi 2014; Dietrich 2004). Our findings indicate that flow may create a strong implicit drive for self-expression, action and creation in relation to brand pages. For example, the Getty Museum Challenge in Los Angeles, in an effort to keep its followers engaged with their art during the COVID-19 pandemic, asked them to recreate a work of art using objects and people from their home. The activity received a high rate of engagement and participation on Twitter, potentially because it was a mentally challenging and exciting activity that elicited flow (Creative Review 2020).

\section{Brand page experiences that drive: self-expansion, self-page inclusion, flow and attachment}

\section{Self-expansion}

According to the findings of this research, flow did not predict self-expansion. A potential explanation is that personal growth may occur after flow states and experiences are processed and some time may be required before the individual can incorporate flow experiences in their sense of self and thus achieve greater self-expansion (Graham 2008). With regard to page experiences that predict self-expansion, whereas Kerviler and Rodriguez (2019) found that intellectual, sensorial and emotional dimensions contribute most to self-expansion for luxury brands, this study highlights that novelty and learning experiences are the most important for self-expansion with regard to social media brand pages. Such brand page experiences are intellectually and emotionally stimulating and therefore may help individuals expand their cognitive, social and emotional skills. Brands should offer new and exciting experiences on their brand pages that differentiate them from other brands. Thus, companies should aim to be positively surprising on their social media pages, e.g., Nike's Instagram posts emphasizing athletic accomplishments of diverse groups (e.g., roller-skating for all bodies and genders, women's boxing group in Shanghai, etc.).

\section{Self-page inclusion}

This research shows that social and relationship experiences on brand pages are the most important for eliciting loyal social media users' self-page inclusion. Research on interpersonal relationships posits that shared activities and interest in the other may enhance intimacy and closeness between partners (Aron et al. 2013; Reis and Shaver 1988). According to our findings, meaningful social interactions may strengthen users' sense of closeness and intimacy with brand pages. Social media users may also establish a sense of common identity with brand pages that appear to show interest in, and commitment to them.

\section{Flow}

Previous studies found that social interactions are important components of flow in social media environments (Carlson et al. 2017a, b; Kaur et al. 2016). Flow may be experienced in a social context, and collective flow may enhance social integration (Páez et al. 2015). According to our results, social experiences contribute the most to flow (in comparison to sensorial, behavioral, intellectual, novelty, functional and entertainment experiences). Thus, flow experienced through brand pages derives from immersive social interactions creating a sense of oneness on brand pages. In addition to social experiences, we show that engaging users' emotions can also facilitate brand page flow via the experience of positive emotional arousal.

\section{Attachment}

Finally, with regard to attachment, social and entertainment experiences are important for promoting attachment with brand pages. According to the findings of this research, loyal fans become more attached to brands that offer opportunities for connection with others, as well as arousing and entertaining experiences that boost positive affect. 


\section{Theoretical implications}

In summary, this research makes a theoretical contribution to the literature on social media and branding by applying self-expansion theory, and the theoretical concepts of selfother inclusion and flow to the study of social media users' relationships with brand pages. It clarifies, in relation to past research that, for loyal fans of social media brand pages, self-expansion and flow are more important constructs for sharing and creation activities than brand page attachment. Further, it provides theoretical understanding of the mechanisms behind self-expansion, flow and self-page inclusion by identifying experiences that can elicit these on social media brand pages. The research also contributes to the selfexpansion literature (e.g., Aron et al. 2000; Kerviler and Rodriguez 2019; Reinman et al. 2012) by highlighting the importance of self-other inclusion, novelty and intellectual experiences for self-expansion. It extends the literature on the implications of flow (Csikszentmihalyi 2014; Dietrich 2004; Carlson et al. 2017a, b) by suggesting that flow is an implicit state that facilitates spontaneous self-expression on social media through the reduction of self-inhibitions. Further, a methodological contribution is offered to the measurement of brand page relationships. An instrument is provided to measure inclusion of the brand page in the self (Fig. 1) that can be a valuable indicator of how close consumers feel to a brand page.

\section{Managerial implications}

\section{Loyal fans' need for self-expansion: implications for brand pages}

Companies are focusing their social media marketing efforts on converting brand page followers to loyal fans, as loyal fans are more likely to become loyal brand customers and advocates (Nisar and Whitehead 2016; Marin 2019). Loyal fans of brand pages are also valuable as they help spread positive word-of-mouth on social media and recommend brands to other social media audiences (Kleine-Kalmer 2015). According to the findings of this research, companies can strongly motivate loyal fans to spread positive word-ofmouth on social media by providing them with opportunities for self-expansion. Brands should provide on their social media pages stimuli that help loyal fans develop their perspectives and skills, expand their sense of identity and help them grow.

Companies such as Nike (\#DreamCrazy) and Dove (\#InMyOwnSkin) have built distinctive brand personalities on social media by actively engaging their loyal fans more, via emotional, inspirational and educational content, rather than merely promotions and sales (Youth Incorporated 2019). The findings of this research specifically stress that in order to elicit sharing and creation activities from loyal fans, brands should primarily focus on adopting an emotional purpose on social media, rather than emphasizing promotions and sales. Companies should inspire loyal fans to improve their lives, offering opportunities for education, cultivation of creativity and interests, enhancement of physical health and exploration of the world. For example, fashion clothing brands that aim to motivate sharing and creation by their loyal fans should identify and communicate on social media an area of self-expansion that resonates with these fans (e.g., being creative with fashion, finding one's own personal style, etc.).

\section{Page experiences and self-expansion: implications for brand pages}

Brands should strive to be unique and different on social media to meet loyal fans' self-expansion needs. Brand pages that are innovative, exciting and have a distinctive personality are deemed as more self-expansive. Unique experiences on brand pages may be stimulating for consumers, enabling them to broaden their perspectives and cultivate their skills. Brand pages should offer novelty not only via distinctive content but also via distinctive communication with fans. For example, Wendy's is highly successful on social media as it has developed a witty and unusual way of conversing with its millennial social media audience (Fast Company 2019). Thus, unique experiences on brand pages are important as they may lead to self-expansion, inspiring loyal audiences to create and share content on behalf of brands they love.

In order to provide self-expansion benefits to their loyal fans and motivate sharing and creation activities, companies should especially curate learning experiences for their brands. They should offer consumers opportunities to acquire new knowledge and develop their skills in specific interest areas. For example, companies could use social media listening tools to identify their audiences' specific interests (e.g., arts, sports, music, cinema, etc.) and depending on their brand's personality, focus on providing learning opportunities in a specific area that interests their audience and fits with the brand. For example, photography brands like Canon and Nikon could address potential interests of their loyal fans relating to art.

\section{Page experiences and flow: implications for brand pages}

Companies should also aim to elicit flow in their social media brand pages, as flow can directly motivate brand page-related sharing and creation. Brands should offer immersive social or emotional experiences on their social media pages in order to elicit flow. For example, companies such as Lego engage their fans to submit new product 
ideas and innovations on their pages (Ecoconsultancy 2020). Brands could further encourage interaction between their loyal social media users, e.g., by inviting them to discuss and develop with them new ideas and innovations on their social media pages.

\section{Page experiences and self-page inclusion: implications for brand pages}

In order to motivate sharing and creation activities, companies should also develop content strategies on brand pages that enhance loyal fans' self-page inclusion. Brands should help consumers establish and maintain social relationships on their pages. They should curate experiences encouraging social interaction, personal disclosure and sharing among members of brand pages. Such experiences provide loyal fans with opportunities to meet, interact and learn from other brand page members with similar interests. Further, companies should focus their social media efforts on creating and nurturing relationship experiences with fans. They should reward fans with loyalty programs, events and special offers catered to their needs. They can also strengthen their relationships by understanding fans' informational needs, and curating content addressing these needs. For example, airline companies can nurture their relationships with fans by providing frequently asked questions (FAQs) on their social media pages with regard to technical and safety aspects of flying.

\section{Limitations and future research}

There are some potential moderators that may influence individuals' motivation for self-expansion that were not examined in this study. Motivation for self-expansion may vary based on individuals' personalities. Some individuals may be more prone to self-expansion and are therefore more driven than others to seek and integrate self-expansive experiences in their lives (Hughes et al. 2019). Thus, social media users, based on their personality traits, may place more or less importance on self-expansion. Motivation for self-expansion may also differ based on age, life stage, socioeconomic status and culture. For example, whereas this study focused on millennial social media users (ages 18 to 34 ), consumers more mature in age may potentially be less motivated by self-expansion and thus be less interested in opportunities for self-expansion from brand pages they follow (Aron et al. 2013).

The study design was cross-sectional and as such, future research should include longitudinal study designs, and additional data analysis methods, such as content analyses and ethnography, as well as including a more diverse sample (based on demographic characteristics like age and gender), in order to expand upon the findings of this research. A longitudinal study would be especially useful in order to examine the long-term effects of flow on selfexpansion. Second, only one social media site, Instagram, was examined. Since social media platforms vary by types of features and interactivity of brand pages, future studies should examine users of other popular social media platforms, including Facebook, Twitter and Snapchat, in order for results to be more generalizable. Future studies should also examine self-expansion benefits in relation to social cause or philanthropic content on brand pages and how self-expansion via such content may influence sharing and creation activities.

In conclusion, this study applied self-expansion theory, along with the theoretical concepts of self-other inclusion and flow, to examine motivations for social media users to share, create content and spread word-of-mouth about brands through social media brand pages. Results suggest that increasing self-expansion, brand page flow and self-page inclusion are effective variables for social media users' interactions with brand pages and should be considered as important strategies by companies when planning their social media marketing activities.

\section{References}

Araujo, T., P. Neijens, and R. Vliegenthart. 2015. What motivates consumers to retweet brand content? Journal of Advertising Research 55(3): 284-295.

Aron, A., G.W. Lewandowski Jr., D. Mashek, and E.N. Aron. 2013. The self-expansion model of motivation and cognition in close relationships. In The Oxford handbook of close relationships, ed. J.A. Simpson and L. Campbell, 90-105. New York, NY: Oxford University Press.

Aron, A., C.C. Norman, E.N. Aron, C. McKenna, and R.E. Heyman. 2000. Couples' shared participation in novel and arousing activities and experienced relationship quality. Journal of Personality and Social Psychology. 78(2): 273-284.

Aron, A., and E.N. Aron. 2006. Romantic relationships from the perspectives of the self-expansion model and attachment theory: Partially overlapping circles. In Dynamics of romantic love: Attachment, caregiving, and sex, ed. M. Mikulincer and G.S. Goodman, 359-382. New York: The Guilford Press.

Aron, E.N., and A. Aron. 1996. Love and expansion of the self: The state of the model. Personal Relationships. 3: 45-58.

Aron, A., E.N. Aron, and D. Smollan. 1992. Inclusion of other in the self, scale and the structure of interpersonal closeness. Interpersonal relations and group processes. Journal of Personality and Social Psychology 63(4): 596-612.

Ashley, C., and T. Tuten. 2015. Creative strategies in social media marketing: An exploratory study of branded social content and consumer engagement. Psychology \& Marketing 32: 15-27.

Bentler, P.M., and D.G. Bonett. 1980. Significance tests and goodness of fit in the analysis of covariance structures. Psychological Bulletin 88(3): 588-606.

Bentler, P.M., and C.P. Chou. 1987. Practical issues in structural modeling. Sociological Methods \& Research 16(1): 78-117. 
Brakus, J.J., B.H. Schmitt, and L. Zarantonello. 2009. Brand experience: What is it? How is it measured? Does it affect loyalty? Journal of Marketing 73(3): 52-68.

Bullock, L. 2019. 15 examples of big brands using user-generated content and how to adapt them for your campaign. Business 2 Community. 18 July, https://www.business2community.com/ content-marketing/15-examples-of-big-brands-using-user-gener ated-content-and-how-to-adapt-them-for-your-campaign-02221 251. Accessed April 2021.

Byrne, B.M. 2010. Structural equation modeling with AMOS. New York, NY: Routledge.

Carlson, J., M.M. Rahman, A. Taylor, and R. Voola. 2017a. Feel the VIBE: Examining value-in-the-brand-page-experience and its impact on satisfaction and customer engagement behaviors in mobile social media. Journal of Retailing and Consumer Services 46: 149-162.

Carlson, J., N. Jane de Vries, M.M. Rahman, and A. Taylor. 2017b. Go with the flow: Engineering flow experiences for customer engagement value creation in branded social media environments. Journal of Brand Management 24: 334-348.

Carpenter, C.J., and E.L. Spottswood. 2013. Exploring romantic relationships on social networking sites using the self-expansion model. Computers in Human Behavior 29(2013): 1531-1537.

Cseh, G.M., L.H. Phillips, and D.G. Pearson. 2015. Flow, affect and visual creativity. Cognition and Emotion 29(2): 281-291.

Csikzentmihalyi, M. 1990. Flow: The psychology of optimal experience. New York: Harper and Row.

Csikszentmihalyi, M. 2014. Flow and the foundations of positive psychology: The collected works of Mihaly Csikszentmihalyi. New York: Springer.

Cohen, N. and J. Flores. 2020. Top 100 millennial brands 2019, Moosylvania. https://moosylvania.com/insights/top-100/. Accessed 13 April 2021.

Creative Review. 2020. Celebrating the social media challenge that got us through lockdown, August, 13, https://www.creativereview.co. uk/getty-social-media-challenge-book/. Accessed 5 March 2021.

Dietrich, A. 2004. Neurocognitive mechanisms underlying the experience of flow. Consciousness and Cognition 13(4): 746-761.

Econsultancy. 2020. 30 brands with excellent social media strategies. 25 June, https://econsultancy.com/30-brands-with-excellentsocial-media-strategies/. Accessed 10 March 2021.

Ellison, N.B., C. Steinfield, and C. Lampe. 2007. The benefits of Facebook "friends:" Social capital and college students' use of online social network sites. Journal of Computer-Mediated Communication 12(4): 1143-1168.

Fast Company. 2019. Behind Wendy's epic social strategy. Fast Company. 18 April, https://www.fastcompany.com/90330377/behindwendys-epic-social-strategy. Accessed 5 March.

Graham, J.M. 2008. Self-expansion and flow in couples' momentary experiences: An experience sampling study. Journal of Personality and Social Psychology 95(3): 679-694.

Hair, J.F., W.C. Black, B.J. Babin, and R.E. Anderson. 2018. Multivariate data analysis: A global perspective, 8th ed. London: Upper Saddle River.

Heinonen, K. 2011. Consumer activity in social media: Managerial approaches to consumers' social media behavior. Journal of Consumer Behavior 10: 356-364.

Hollenbeck, C.R., and A.M. Kaikati. 2012. Consumers' use of brands to reflect their actual and ideal selves on Facebook. International Journal of Research in Marketing 29(2012): 395-405.

Homans, G.C. 1958. Social behavior as exchange. American Journal of Sociology 63(6): 597-606.

Hogarty, Kristine Y., Constance V. Hines, Jeffrey D. Kromrey, John M. Ferron, and Karen R. Mumford. 2005. The quality of factor solutions in exploratory factor analysis: The influence of sample size, communality, and overdetermination. Educational and Psychological Measurement 65(2): 202-226.

Hogg, M.A., and E.A. Hardie. 1991. Social attraction, personal attraction and self-categorization: A field study. Personality and Social Psychology Bulletin 17(2): 175-180.

Hogg, M.A., D.J. Terry, and K.M. White. 1995. A tale of two theories: A critical comparison of identity theory with social identity theory. Social Psychology Quarterly 58(4): 255-269.

Hubspot. 2020. Report: Not another state of the market report. https:// www.hubspot.com/state-of-marketing. Accessed 5 May 2021.

Hu, L., and P.M. Bentler. 1998. Fit indices in covariance structure modeling: Sensitivity to underparameterized model misspecification. Psychological Methods 3(4): 424-453.

Hu, L.T., and P.M. Bentler. 1999. Cutoff criteria for fit indexes in covariance structure analysis: Conventional criteria versus new alternatives. Structural Equation Modeling 6(1): 1-55.

Hughes, E.K., E.B. Slotter, and G.W. Lewadowski. 2019. Expanding who I am: Validating the self-expansion preference scale. Journal of Personality Assessment 102(6): 792-803.

John, L.K., O. Emrich, S. Gupta, and M.I. Norton. 2017. Does "liking" lead to loving? The impact of joining a brand's social network on marketing outcomes. Journal of Marketing Research 54(1): 144-155.

Kaur, P., A. Dhir, and R. Rajala. 2016. Assessing flow experience in social networking site based brand communities. Computers in Human Behavior 64: 217-225.

Kerviler, G., and C.M. Rodriguez. 2019. Luxury brand experiences and relationship quality for Millennials: The role of self-expansion. Journal of Business Research 102: 250-262.

Kleine-Kalmer, B. 2015. Brand page attachment: An empirical study on Facebook users' attachment to brand pages. Gabler: Springer.

Kim, D., L. Spiller, and M. Hettche. 2015. Analyzing media types and content orientations in Facebook for global brands. Journal of Research in Interactive Marketing 9(1): 4-30.

Kline, Rex B. 2015. Principles and practice of structural equation modeling. New York, NY: Guilford Publications.

Kwak, K.T., S.K. Choi, and B.G. Lee. 2014. SNS flow, SNS selfdisclosure and post hoc interpersonal relations change: Focused on Korean Facebook user. Computers in Human Behavior 31: 294-304.

Lewandowski, G. and A. Aron. 2002. The self-expansion scale: Construction and validation. Paper presented at Annual Meeting of the Society of Personality and Social Psychology; 2 February, Savannah,Georgia, U.S.

Lewandowski, G.W., and R.A. Ackerman. 2006. Something is missing: Need fulfillment and self-expansion as predictors of susceptibility to infidelity. The Journal of Social Psychology 146(4): 389-403.

Lipsman, A., G. Mudd, M. Rich, and S. Bruich. 2012. The power of "like" how brands reach (and influence) fans through social-media marketing. Journal of Advertising Research 52(1): 40-52.

Marine, C. 2019. Amplify social brand communities to boost customer loyalty. Strategic Social Media Lab. https://strategicsocialmedia lab.com/amplify-social-brand-communities-to-boost-customerloyalty/. Accessed 3 April 2021.

MacCallum, R.C., K.F. Widaman, Z. Shaobo, and S. Hong. 1999. Sample size in factor analysis. Psychological Methods 4(1): 84-99.

Mattingly, B.A., and G.W. Lewandowski. 2013. The power of one: Benefits of individual self-expansion. The Journal of Positive Psychology 8(1): 12-22.

Mattingly, B.A., and G.W. Lewandowski. 2014a. Expanding the self, brick by brick: Nonrelational self-expansion and self. Social Psychological and Personality Science 5(4): 484-490.

Mattingly, B.A., and G.W. Lewandowski. 2014b. Broadening horizons: Self-expansion in relational and non-relational contexts. Social and Personality Psychology Compass 8(1): 30-40. 
McIntyre, K.P., B.A. Mattingly, G.W. Lewandowski, and A. Simpson. 2014. Workplace self-expansion: Implications for job satisfaction, commitment, self-concept clarity, and self-esteem among the employed and unemployed. Basic and Applied Social Psychology 36: 59-69.

Muntiga, D.G., M. Moorman, and E.G. Smit. 2011. Introducing COBRAs exploring motivations for brand-related social media use. Journal of International Advertising 30(1): 13-46.

Nikolinakou, A., and J. Phua. 2020. Do human values matter for promoting brands on social media? How social media users' values influence valuable brand-related activities such as sharing, content creation, and reviews. Journal of Consumer Behavior. 19(1): $13-23$.

Nisar, T.M., and C. Whitehead. 2016. Brand interactions and social media: Enhancing user loyalty through social networking sites. Computers in Human Behavior. 62: 743-753.

Nysveen, H., P.E. Pedersen, and S. Skard. 2013. Brand experience in service organizations: Exploring the individual effects of brand experience dimensions. Journal of Brand Management 20(5): 404-425.

Páez, D., B. Rimé, N. Basabe, A. Wlodarczyk, and L. Zumeta. 2015. Psychosocial effects of perceived emotional synchrony in collective gatherings. Journal of Personality and Social Psychology 108(5): 711-729.

Park, C.W., D.J. Macinnis, J. Priester, A.B. Eisingerich, and D. Iacobucci. 2010. Brand attachment and brand attitude strength: Conceptual and empirical differentiation of two critical brand equity drivers. Journal of Marketing 74(6): 1-17.

Patwardhan, H., and S.K. Balasubramanian. 2011. Brand romance: A complementary approach to explain emotional attachment toward brands. Journal of Product \& Brand Management 20(4): 297-308.

Pelet, J.-E., S. Ettis, and K. Cowart. 2017. Optimal experience of flow enhanced by telepresence: Evidence from social media use. Information and Management 54(1): 115-128.

Pew Research Center. 2019. Share of U.S. adults using social media, including Facebook, is mostly unchanged since 2018. 10 April. https://www.pewresearch.org/fact-tank/2019/04/10/share-of-u-sadults-using-social-media-including-facebook-is-mostly-uncha nged-since-2018/. Accessed 11 March 2021.

Phua, J., S.V. Jin, and J. Kim. 2017. Gratifications of using Facebook, Twitter, Instagram, or Snapchat to follow brands: The moderating effect of social comparison, trust, tie strength, and network homophily on brand identification, brand engagement, brand commitment, and membership intention. Telematics and Informatics 34: 412-424.

Reimann, M., R. Castaño, J. Zaichkowsky, and A. Bechara. 2012. How we relate to brands: Psychological and neurophysiological insights into consumer-brand relationships. Journal of Consumer Psychology 22: 128-142.

Reimann, M., and A. Aron. 2009. Self-expansion motivation and inclusion of close brands in self: Towards a theory of brand relationships. In Handbook of brand relationships, ed. J. Priester, D. MacInnis, and C. Park, 65-81. M.E. Sharpe: New York, NY.

Reis, H.T., and P. Shaver. 1988. Intimacy as an interpersonal process. In Handbook of relationships, ed. S.W. Duck, 367-389. Chichester: Wiley.

Social Media Today. 2018. The real benefits of user generated content. 9 November, https://www.socialmediatoday.com/news/the-realbenefits-of-user-generated-content/541890/. Accessed 9 Feb 2021.

Social Media Today. 2019. How to use storytelling to connect with your audience on Instagram. 19 June, https://www.socialmediatoday. com/news/how-to-use-storytelling-to-connect-with-your-audie nce-on-instagram/556989/. Accessed 19 Feb 2021.

Schivinski, B., G. Christodoulidis, and D. Dabrowski. 2016. Measuring consumers' engagement with brand-related social-media content. Journal of Advertising Research 56(1): 64-80.

Skadberg, Y.X., and J.R. Kimmelb. 2004. Visitors' flow experience while browsing a Web site: Its measurement, contributing factors and consequences. Computers in Human Behavior 20(2004): $403-422$.

Sprout. 2020. The Sprout Social Index, Edition XV: Empower and Elevate. Sprout Index Report. https://media.sproutsocial.com/ uploads/2020-Sprout-Social-Index-Above-and-Beyond.pdf?utm_ medium $=$ Emailandutm_content $=$ GuideTrigger. Accessed $15 \mathrm{Jan}$ 2021.

Statista. 2019. Social media marketing usage rate in the United States from 2013 to 2019. https://www.statista.com/statistics/203513/ usage-trands-of-social-media-platforms-in-marketing/. Accessed 2 March 2021.

Schumacker, R.E., and R.G. Lomax. 2004. A beginner's guide to structural equation modeling. Mahwah, NJ: Lawrence Erlbaum Associates.

Tafesse, W. 2016. An experiential model of consumer engagement in social media. Journal of Product and Brand Management 25(5): 424-434.

Van Meter, R., H.A. Syrdal, S. Powell-Mantel, D.B. Grisaffe, and E.T. Nesson. 2018. Don't just "like" me, promote me: How attachment and attitude influence brand related behaviors on social media. Journal of Interactive Marketing 43: 83-97. https://doi.org/10. 1016/j.intmar.2018.03.003.

Walker, C.K. 2010. Experiencing flow: Is doing it together better than doing it alone? The Journal of Positive Psychology 5: 3-11.

Wang, G. 2002. Attitudinal correlates of brand commitment: An empirical study. Journal of Relationship Marketing 1(2): 57-75.

Yılmaz, H., and E. Enginkaya. 2015. Brand followers: Motivations and attitudes of consumers to follow brands in social media. International Journal of Internet Marketing and Advertising 9(1): 3-120.

Yuki, T. 2015. What makes brands' social content shareable on Facebook? An analysis that demonstrates the power of online trust and attention. Journal of Advertising Research 55(4): 458-470.

Youth Incorporated. 2019. Five brilliant ad campaigns that will blow your mind, 22 June. https://youthincmag.com/5-brilliant-adcampaigns-that-will-blow-your-mind. Accessed 11 June 2021.

Zafirovski, M. 2005. Social exchange theory under scrutiny: A positive critique of its economic-behaviorist formulations. Electronic Journal of Sociology. http://citeseerx.ist.psu.edu/viewdoc/downl oad?doi=10.1.1.454.7467andrep=rep1 andtype=pdf. Accessed 11 June 2021.

Zaglia, M.E. 2013. Brand communities embedded in social networks. Journal of Business Research 66(2): 216-223.

Publisher's Note Springer Nature remains neutral with regard to jurisdictional claims in published maps and institutional affiliations.

Angeliki Nikolinakou ( $\mathrm{PhD}$, University of Georgia) has worked as an Assistant Professor of Advertising in the University of Southern Mississippi. Her research examines advertising, branding and strategy in new media. Her studies have appeared in the Journal of Consumer Behavior, Psychology and Marketing, and Journal of Current Issues in Research and Advertising. 
Joe Phua is an Associate Professor in the Department of Advertising and Public Relations in the Grady College of Journalism and Mass Communication at the University of Georgia. His research examines advertising, branding and strategic communication in computer-mediated contexts. His studies have appeared in the Journal of Communication, Journal of Advertising, Journal of Health Communication, and Computers in Human Behavior, among others.
Eun Sook Kwon (PhD, University of Georgia) is an assistant professor of advertising in the School of Communication at Rochester Institute of Technology. Her research focuses on consumer-brand relationships in social media, advertising/media engagement and replication practices. Her studies have appeared in the European Journal of Marketing, International Journal of Advertising, Journal of Advertising Research and Journal of Business Research among others. 